\title{
Biology and Harmfulness of Lepidoptera (Insecta: Lepidoptera) Damaging Generative Organs of Saxaul (Chenopodiaceae : Haloxylon) in the South-East desert Area of Kazakhstan
}

\author{
Nagima Toktasinovna Tumenbayeva ${ }^{1}$, \\ Bagdavlet Turalievich Taranov ${ }^{1}$ and Vili Borisovna Harizanova ${ }^{2}$ \\ ${ }^{1}$ Kazah National Agrarian University, Abaya avenue, 8, Almaty, 050010, Kazakhstan. \\ ${ }^{2}$ Agricultural University - Plovdiv, Mendeleev blvd., 12, Plovdiv, 4000, Bulgaria.
}

http://dx.doi.org/10.13005/bbra/2122

(Received: 02 April 2016; accepted: 01 May 2016)

\begin{abstract}
Insects, as one of the most important biogenic factors that have a significant impact on the survival of seedlings and productivity of Saxaul (Haloxylon). Eating or developing in the inside of the trunk, branches, shoots, leaves, roots, flowers and fruits, they cause significant changes in the composition and structure of plant communities, negatively affect the lifespan of plants, and overall for productivity of the grassland. In studies conducted in the desert area of the South-East of Kazakhstan we registered 35 species of Lepidoptera on the Saxaul (Haloxylon) that were trophically associated with different organs, and among them 8 species were as the potential pests of generative organs.
\end{abstract}

Key words: Saxaul (Haloxylon), pests, Lepidoptera, harmfulness.

Since the end of the twentieth century worldwide significantly increased the size of the desertification because of the abiotic and anthropogenic factors. According to the report of the 4th GEF Assembly in 2010 the $24 \%$ of land worldwide is degraded; among them for about 20$25 \%$ of degrading land is rangeland ${ }^{1}$. In Kazakhstan since the 60 -ies the territory of desertification increased by $10-12 \%$.

Desert and semi-desert areas of Kazakhstan occupy a large area - more than 124 million hectares. Forests in Kazakhstan are rear and they differ greatly from other forests in the world. Saxaul forest occupies $49.7 \%$ out of 26.7 million hectares of the forest fund of Kazakhstan (about 15 million hectares) $)^{2}$. Saxaul forest zones form a special type of desert vegetation and they play a huge role in maintaining the balance of the

\footnotetext{
* To whom all correspondence should be addressed.
}

desert ecosystem. In addition they clamp sands, protect pastures and have a sanitary-hygienic value. Clamping the huge masses of sandy and sandy loam soils, they protect oases, channels, transport roads, pipelines and industrial objects from the filling of sand and increase pasture productivity.

In recent years, in the desert area of South and South-Eastern Kazakhstan in the fight against desertification a reforestation is conducted. For example, in Kyzylorda by the AASB (Afforestation of the Aral Sea Bed) program of the World Bank in 2015 year the cultivation of Haloxylon was produced on more than 79 thousand hectares. State Institution for the protection of forests and wildlife in Zhambyl and Almaty areas annually produced crops of Saxaul in average of 400-500 ha. The expansion of artificial areas of Saxaul depends upon many abiotic and biotic factors, and the survival rate of seedlings is very low. 
Insects, as one of the most important biogenic factors that have a significant impact on the survival rate of seedlings and on the vegetative productivity of Saxaul. Caterpillars of Lepidoptera are eating the young shoots, leaves and generative organs of Saxaul. Developing in the inside of the trunk, branches, roots, flowers and fruits, they inhibit the growth and longevity of plants. Their mass reproduction changes the composition and structure of plant communities, reducing the productivity of forage lands ${ }^{3,4}$. The harmful activities of Lepidoptera play a special role in the damaging of the generative organs of Saxaul ${ }^{5,6}$. Their harmful activities spreading over the large areas, reduce the biomass of plants up to $30 \%$, and seeds productivity for more than $30 \%$, in some areas up to $80 \%{ }^{7}$.

The important issues in combating major pests of generative organs of Saxaul are the establishing of harmfulness and the vulnerable stages of development of insects.

\section{MATERIALSANDMETHODS}

The basis for this work was the materials collected by authors in the deserts of Sariesikatirau, the Moyinkum and the Taukum in 2014-2015. Faunal collections and observations of the biology of harmful of Lepidoptera were carried out starting from the second decade of April till the second decade of October in Saxaul forests and crops of the State institution for the protection of forests and wildlife in Zhambyl and Almaty areas.

The harmfulness identification of collected species of Lepidoptera was carried out by the laboratory staff "Taxonomy of insects" Sinew S. Y., Mattov A. Y. "Institute of Zoology" Russian Academy of Sciences of Saint-Petersburg and by Yakovlev R.V. (FSBAO HPE "Altai State University”, Barnaul, Russia). We express them a great gratitude.

During the fieldwork for the collection of Lepidoptera faunal material were used the generally accepted methods in entomology $y^{8-10}$ with the following modifications: a monitoring of caterpillars nutrition of the various organs of Saxaul was carried out in a night time; for catching of imago was used a gasoline generator with output power of $1 \mathrm{~kW} /$ hour and a 500 watts luminescent lamp.

To determine the total number (population density) of caterpillars of Lepidoptera in some parts of Saxaul, the average number of caterpillars on a single tree of 10 trees was calculated. In the autumn the number of Saxaul seeds and its damage were determined. From the total mass of collected seeds was chosen $1 \mathrm{~kg}$. After that by a method of quartering was selected a certain number of seeds for the further conduction of practices in assessing the damage and germination.

Table 1. Definition of a voracity of caterpillar of Orgyia dubia Tausch. Bakanas, may 2015

\begin{tabular}{lcccc}
\hline Variants & $\begin{array}{c}\text { The number of } \\
\text { caterpillars in } \\
\text { options }\end{array}$ & $\begin{array}{c}\text { The average number of } \\
\text { leaves on single branches }\end{array}$ & $\begin{array}{c}\text { The average number of } \\
\text { damaged leaves }\end{array}$ & $\begin{array}{c}\text { The number of damaged } \\
\text { leaves in \% }\end{array}$ \\
\hline 1 & 3 & 25 & 5 & 20 \\
2 & 5 & 25 & 7 & 28 \\
3 & 7 & 25 & 12 & 68 \\
4 & 10 & 25 & 17 & 68 \\
\hline
\end{tabular}

Table 2. The harmfulness of caterpillars of Phtheochroa subfumida

Hysterosia subfumida Flkv., September-October, Bakanas, 2015

\begin{tabular}{lccc}
\hline $\begin{array}{l}\text { The number of } \\
\text { caterpillars per one plant }\end{array}$ & $\begin{array}{c}\text { The number of seeds on } \\
\text { 1 branche of Haloxylon }\end{array}$ & $\begin{array}{c}\text { The number of damaged seeds } \\
\text { on 1 branch of Haloxylon }\end{array}$ & $\begin{array}{c}\text { The percentage of } \\
\text { damaged seeds }\end{array}$ \\
\hline 10 & 210 & 57,33 & 27,3 \\
25 & 210 & 89,25 & 42,5 \\
50 & 210 & 181,89 & 86,6 \\
Control & 210 & - & - \\
\hline
\end{tabular}




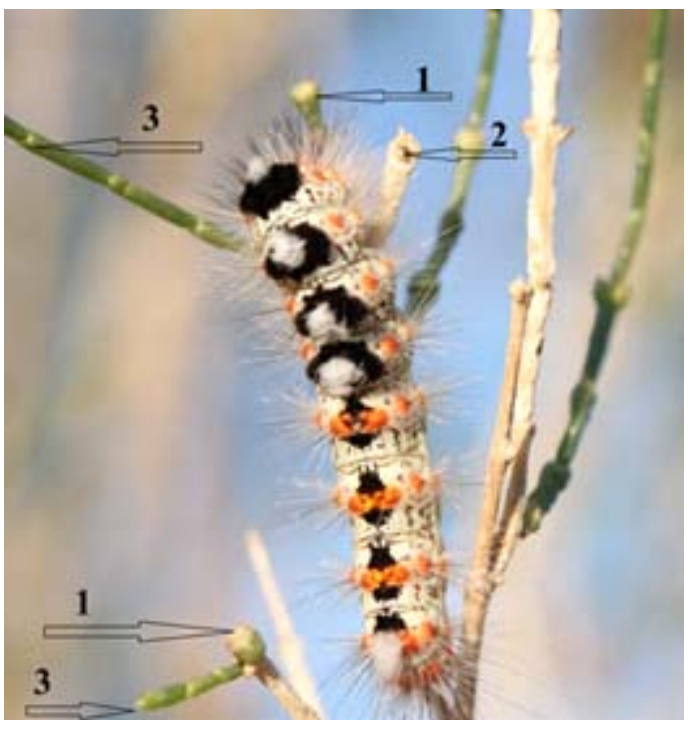

Fig. 1. Caterpillar of Orgyia dubia Tausch. Is damaging the assimilating shoots: 1 - damaged shoots, 2 - damaged shoots of last year, 3- undamaged shoots

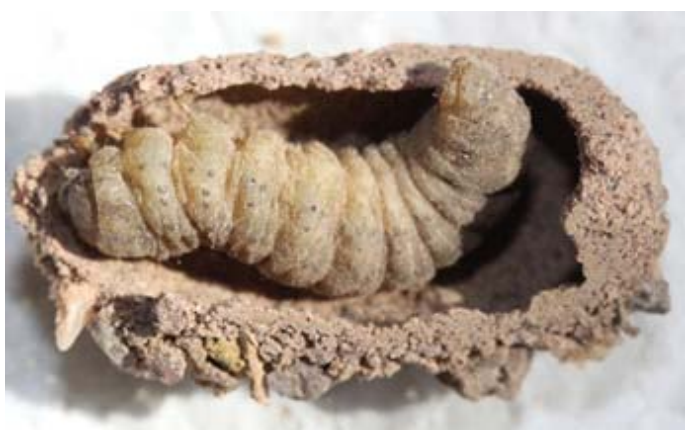

Fig. 2. Caterpillar of Pseudohadena immunda in a ground cocoon before pupation

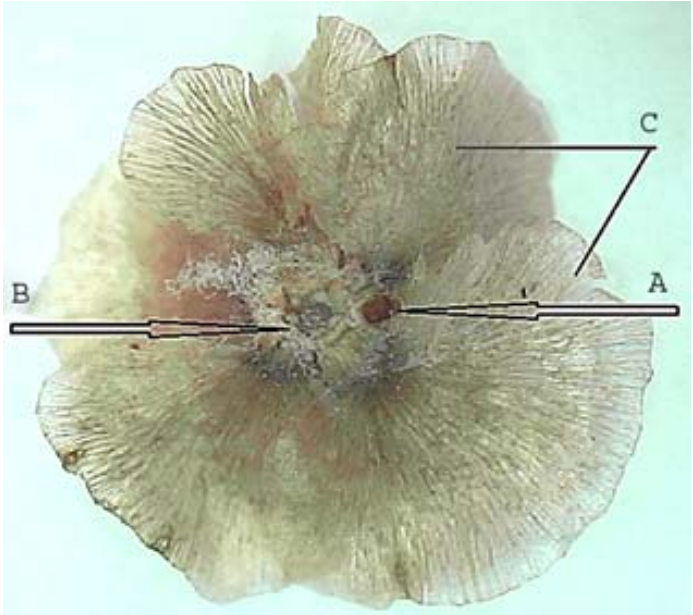

Fig. 3. A-outlet of the caterpillar, B-receptacle, C-petals
The harmfulness of caterpillars of Orgyyia dudia Tausch. and Hysterosia subfumida Flkv. was carried out in special cages that were placed on the twigs of plants. Were added for 10 caterpillars of middle age (at this age would be carried out tests with insecticides). The number of healthy leaves was counted before adding the caterpillars, then in 5 days after adding and in the end of experiment development was counted the number of damaged leaves and fruits. The harmfulness of caterpillars was rechecked four times.

The harmfulness damaging of seeds by caterpillars was determined by the coefficient of harmfulness $-\mathrm{q}$ [11], by the formula:

$$
q=\frac{(a-b)}{a} \cdot 100
$$

where,

$\mathrm{q}$ - a coefficient of harmfulness;

$\mathrm{a}-$ is the number of intact organs (seed);

$\mathrm{b}-$ is the number of damaged organs (seeds).

In autumn after the harvest of the seeds of Haloxylon was determined the degree of damage by caterpillars of Gelechiidae and the Case-bearer. Samples of seeds were taken from 10 trees; the collected seeds of Haloxylon were carefully mixed, and then by a method of quartering was left the required number of seeds. After that the number of damaged seeds and the number of caterpillars in this sample was counted. In laboratory was determined the weight of 1000 seeds, among 100 seeds was counted the number of damaged, nondamaged seeds and the number of caterpillars per $1 \mathrm{~kg}$.

To test the influence of insecticides against many species of caterpillars that are damaging generative organs of Saxaul (Haloxylon) were selected insecticides from the "List of pesticides (agricultural chemicals), approved for use on the territory of the Republic of Kazakhstan for 2013-2022" 12 .

\section{The discussion and results}

The studies conducted in the desert area of the South-East of Kazakhstan we registered 35 species of Lepidoptera on the Saxaul that were trophically associated with different organs, and among them 8 species were as the potential pests of generative organs ${ }^{6}$. Their development and feeding by the generative organs are associated 

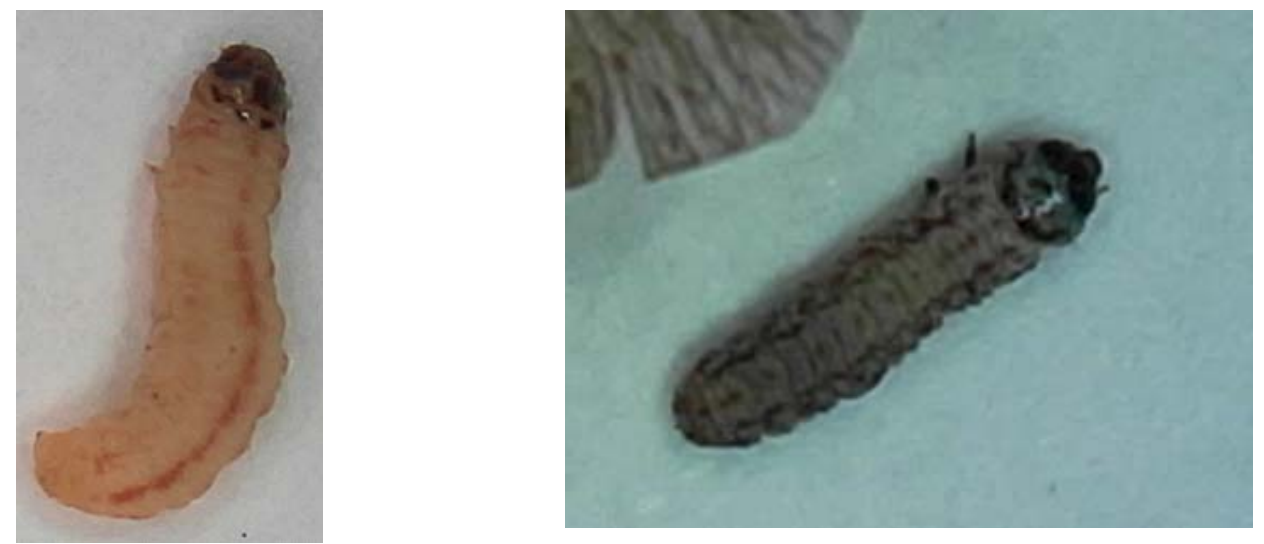

Fig. 4. The caterpillars of Case-bearer (A) and Hysterosia subfumida (B) are damaging seeds of Saxaul

with biological features development of Saxaul and are divided into two seasons: spring species, that are damaging flowers and autumn species damaging seeds or fruits of Saxaul.

\section{Biology of Lepidoptera that are damaging generative organs of Saxaul}

In terms of deserts, seasonal and trophic relations of insects with Saxaul, including Lepidoptera are multifaceted. They are characterized with a synchronous development of the host plants and their organs. For example, during the growing period of Saxaul, harmfulness of Lepidoptera that are damaging generative organs appears twice: in spring, when the plant is in the phase of flowering and autumn, when we see the formation of fruits (seeds). Below is the resulting data on the biology and food relations and the harmfulness of some species of Lepidoptera inhabiting of Saxaul.

Orgyia dubia Tausch ( Lepidoptera: Erebidae, Orgyidae)

Is widespread in Europe, North Africa, Central Asia, Central Asia ${ }^{13-15}$. In Kazakhstan is widespread in the zone of deserts and semi-deserts everywhere. As a pest of Saxaul was marked by the researches Parfentiev V. J. and Nurmuratov T. $\mathrm{N}^{7,16}$.

\section{Morphology}

The wingspan of the male Orgyia dubia is from 18 to $25 \mathrm{~mm}$. Length of a tendril is equal to the third part of the body. Front fender is off-white and yellowish, with brown wavy lines. Female Orgyia dubia is wingless, vermiform, chunky, thorax and abdomen are yellowish, length is up to
$20 \mathrm{~mm}$. The egg is whitish globular-smooth, with a diameter of about $1.5 \mathrm{~mm}$. The adult caterpillar is cylindrical, with a length from $15 \mathrm{~mm}$ to $30 \mathrm{~mm}$. On the dorsal side, starting from the fourth body segment it has four black beams, with the middle of white colour, the same figure is on the last segment (Fig.1). Bristle-like hairs are white and black, of different lengths, they are arranged on colored bumps (mostly black, white and orange), and all over the body are grouped in a bunch. Pupa is yellowish, in a silky cocoon, covered with sparse hairs.

\section{Biology}

According to our observation, the first caterpillars appear in late April, and in some years (in cold spring) - at the beginning of May. The peak of their appearance is at the end of May. According to V.Ya. Parfentyev ${ }^{16}$ Orgyia dubia develops in two generations. The first generation is in the beginning of June and the second generation is in the late of July or early in August. Caterpillars are active during the morning and evening hours of the day.

\section{Harmfulness}

Caterpillars of the first generation of Orgyia dubia damage the assimilating shoots or leaves and generative organs of Saxaul. Damaging the assimilating shoots they stop their further growth, thereby prevents the formation of generative organs and the supply of nutrients to the plant. As the result the shoots dry up, where the generative organs do not generate (Fig. 1). For the definition of voracity of caterpillars of the middle ages (mainly 3) of Orgyia dubia, were 
selected an equal branches of Saksaul with 25 asimilitude shoots (leaves) left, almost the same length (average length of shoots is $10 \mathrm{~cm}$ ). At the end of caterpillars feeding (before pupation) was counted the number of damaged leaves. The results obtained are shown in table 1 .

The table shows that if the number of caterpillars is three on one branch, the plant loses $20 \%$ of assimilatory leaves within 12 days, respectively $5-28 \%, 7-10 \%$ and $48-68 \%$. Thus, if the number of caterpillars of Orgyia dubia is three on one branch of Saxaul it is necessary to conduct a chemical treatment.

\section{Pseudohadena immunda Ev}

A light brown butterfly with a wing span of $40-45 \mathrm{~mm}$.

\section{Biology}

The caterpillars appear in late March and early April. Their full development is completed at the end of May. Then the caterpillars pupate in the vicinity of plants, in the ground cocoon (Fig. 2) at a depth of $10 \mathrm{~cm}$. In late May and early June the imago appears, their maximum occurrence is observed in mid-June. With the onset of hot summer (August) the appearance of imago is almost finished. Further from the end of September till the early October oviposition happens. The eggs are discharged under the plant in crevices on the surface of the soil. They are very solid, ranging in size from $1 \mathrm{~mm}$ to $1.5 \mathrm{~mm}$.

\section{Harmfulness}

Pseudohadena immunda from time to time, gives mass reproduction. On pastures of Betpakdala in 1967 the number of caterpillars reached for 124 per $1 \mathrm{~m}^{2}$ on the area of 500 thousand hectares, and in 1969 in the Ili basin deserts their harmfulness is marked on the area of 50 hectares. At the same time on one bush of Saksaul with a height of $90 \mathrm{~cm}$ there were 162 caterpillars, with a height of $45 \mathrm{~cm}$ there were 118 caterpillars $[17,18]$.

The harmfulness of Hysterosia subfumida Flkv., on Saxaul. In the years of observation in the South Pribullshje were met in a big mass 1 species of Hysterosia subfumida and 1 species of the Case-bearer which are the main pests of seeds of Saxaul. The nature and time of damage to these species it similar. Both are developing inside the seeds (Fig.3 and 4).

During the study period we have studied the harmfulness of Hysterosia subfumida and Case- bearer. The results of these surveys are shown in table 2.

The period of harmfulness activity of Phtheochroa subfumida is 25-30 days. During its development one caterpillar eats up on average from 5.7 to 18.8 seeds of Saxaul. The harmfulness of Phtheochroa subfumida depends on the size, weather conditions and other reasons.

\section{CONCLUSION}

In studies conducted in the desert area of South-East of Kazakhstan we registered 35 species of Lepidoptera on the Haloxylon that were trophically associated with different organs, among them 8 species as the potential pests of generative organs. Their development and feeding by the generative organs are associated with biological features development of Haloxylon and are divided into two seasons: spring species, that are damaging flowers and autumn species - damaging seeds or fruits of Haloxylon.

Species diversity of Lepidoptera leaving on Haloxylon are subdivided into the following family: Cossidae - Teredo; Tortricidae - Leafroller - 1; Coleophoridae - the Case-bearer -2; Scythrididae- Flower moths -2; Gelechiidae Twirler moths -1; Pyralidae - Snout moths -3; Sphingidae - Hawk moths -1; Zygaenidae Burnet or Forester moths -1; Geometridae Inchworms -1; Lasiocampidae - Eggars, Snout moths, or Lappet moths -1; Noctuidae - Owlet moths -17; Arctiinae - Erebid moths-2; OrgyidaeOrgids-1. The pests are divided into different groups depending upon the plant organs they affect: pests of shoots of 12 species, shoots and leaves -9 , shoots and seeds 3 , shoots, leaves and seeds of -1 seeds -4 , leaves -3 , and the stem -1 , root -1 , stem -1 . According to the trophycal specialization they are subdivided into: monophagy - 2 types, narrow oligophagy - 12, olygophages -2 , wide oligophagy -8 and polyphages -11 .

\section{REFERENCES}

1. Data from the report of the 4th GEF Assembly "New science, new opportunities for GEF-5 and its aftermath”, 2010

2. Forest encyclopedia: In 2 volumes, V. 2/Ch.ed. 
Vorob’ev G. I.; Ed.Col.: Anuchin N. A., Atrohin V.G., Vinogradov V. N. and others - M.: Soviet encyclopedia, 1986. p.631, illustr.

3. Nurmuratov T. N. The harmfulness of Lepidoptera-pests of fruits and seeds of Haloxylon in South-Eastern Kazakhstan // Bull. of agric.science. Alma-ATA, 1971; 2: 98-101.

4. Nurmuratov T. N. About the harmfulness of the insects inhabiting Haloxylon // Protection of forage crops from pests and diseases in Kazakhstan. Alma - ATA, 1979. p. 119-129.

5. Taranov, B. T. Insect pests of generative organs of Haloxylon. Modern ecological state of the Aral sea region, the prospects of solving the problems: Internat. Scientific.-Practical.Conf.Kyzylorda.-2011; 92-94.

6. Tumenbaeva N.T, Taranov B.T, Grekov D, Harizanova V. Lepidopteran species (Insecta: Lepidoptera) feeding on saxauls (Chenopodiáceae: Íàloxylon) in desert areas of South-Eastern Kazakhstan.

7. Nurmuratov.T.N. About a mass multiplication of scoops (Pseudohadena immunda Ev., Lepidoptera, Noctuidae) in the deserts of the Ili Depression // Probl. of deserts. Ashgabat, 1973; 5: 70-72.

8. Fasulati K. K. A field study of the insects of invertebrates.-M.: Higher school, 1971; 424.

9. Dobrovolsky, B.V. Phenology of the insects. M.: Higher school, 1969; 219.

10. Tanskii, V. I. Application of economic thresholds of harmfulness of the main pests of major crops (methodical instructions). Leningrad: VIZR, 1985; 27

11. Methodical instructions for accounting and identification of harmful and especially dangerous harmful organisms of agricultural land. Responsible for the issue Suleimenova Z.Sh. Astana: Center for rapid printing, 2009; 312.

12. "The list of pesticides (agricultural chemicals), approved for use on the territory of the Republic of Kazakhstan for 2013-2022”.

13. Patrice Leraut, Moths of Europe, Gaëtan du Chatenet (prefazione); Nicholas Flay (traduzione in inglese); Gilbert Hodebert (disegni), I (Saturnids, Lasiocampids, Hawkmoths, Tiger Moths...), $1^{\text {a }}$ edizione, Verrières-le-Buisson, N.A.P., novembre 2006, pp. 112, tav. 36, figg. 8-11.

14. Fauna Europaea, faunaeur.org. URL consultato il 12 dicembre 2012.

15. U. Nardelli, Giandolfo, B., Biologische und ethologische Angaben über eine der am wenigsten bekannten Lymantriiden von Sizilien: Orgyia dubia arcerii Ragusa, 1923 (Lepidoptera: Lymantriidae), in Nachrichten des entomologischen Vereins Apollo (N. F.), 2000; 21: 123-128.

16. Parfentiev V. J. Pests of Haloxylon in southern Trans-Balkhash area. The research works of Science Researching Institute on plant protection. 1958; 4: 129-141.

17. Nurmuratov T. N. Insects and rodents that inhabitate the desert pastures of South-Eastern Kazakhstan. Almaty: “Angy”, 1998. p.288.:illustr.

18. Shek G.H., Stepanov E. A. About the mass occurrences of desert scoops PseudohadenaimmundaEv. (Iepidoptera, Noctuidoe). Tr.Kazniizr. Alma-ATA, 1972; 11: 145-149. 